\title{
The Influence of Cultural Type on Art Marketing and Recommendation: Focus on the Moderation Effect of Price
}

\author{
Gantumur Khongorzul ${ }^{1}$, Jeong Suk Noh ${ }^{2}$ and Hyong Yu Jang ${ }^{3 *}$ \\ ${ }^{1,2,3}$ Dept. of Business Administration, Gyeongsang National University, 501, Jinju- \\ Daero, Jinju 660-701, South Korea \\ ${ }^{1}$ mishkaa@nate.com, ${ }^{2}$ calfs2002@hanmail.net, ${ }^{3 *}{ }^{*} m g t 21 @ g n u . a c . k r$
}

\begin{abstract}
It is defined that the 21st century is the era of information and technology. The 21st century is changing to a period of culture and art. The most representative and emerging elements of cultural marketing are cultural promotion, cultural synthesis and cultural style. This study not only analyzes empirical effects of cultural marketing on art marketing but also reveals how art marketing has an influence on recommendation. In addition, we analyzed empirical effects of cultural marketing and art marketing on recommendation depending on premium price, showing the strategies that enlarge the company identity based on cultural context. Two preliminary researches have been conducted through 25 marketing professors and graduate course students in order to choose products, brand name and artworks, which would match with the purpose of this study. The conclusion of this study shows that the cultural marketing has partial effects on the art marketing. It also has partial effects on art marketing depending on the premium price. Finally, the premium price has positive moderate effects on recommendation of art marketing.
\end{abstract}

Keywords: Cultural Type, Art Marketing, Recommendation, Premium Price

\section{Introduction}

It can be defined that the 21 st century is the era of information and technology. The 21 st century is changing into a period of culture and art. At 2007, LG Electronics released a new product called "Art Dios". This product shows a flower shape ornament with many Swarovski crystals in red refrigerator. Products Art Dios was released in 34 countries around the world and popular in Europe, Latin America and central Asia. This product was at global hit of goods.

The LG Electronics attained the sale of 3.1 billion from last year in the refrigerator field and climbed up the world's second.

The sales share of premium refrigerators has increased dramatically due to the sale of Art Dios. In recent years, consumers have preferred the art design combined with the product. In addition, many companies want to take advantage of the cultural arts as a major marketing strategy such as product design, promotion, pricing and distribution [1].Consumers are not only more economical in cultural context, but also willing to pay a premium price for a beautiful product [2]. Changes have taken place in the company's business environment and increasing number of consumers consumes the culture. Companies have been trying to satisfy the customer through a variety of sensory experiences including aesthetics and symbolism than the functional differentiation of products. Therefore, companies have been increasing their selection of art and design as marketing means [3]. Cultural symbol and image influence of consumer product choice than function, in

${ }^{*}$ Corresponding Author 
study of Sorman [4] has emerged as a new marketing strategy. Contemporaries claim consumer goods because of cultural symbols and images than function. In recent years a company's culture marketing has emerged to an optimum marketing strategy that responds to chronological changes and changes in consumer [5].

Companies have increased interest in culture and art marketing, the art marketing effect research needs empirical analysis from a practical and theoretical perspective while increase succession cases using a various works of art. Referring to a previous research about culture and art marketing, many researches were conducted about company images (Nam, [6]; Kwak, [7]; Gan et al., [8]; Ryu and Park, [9]) and art advertisement (lee, [10]; Leem and Lee, [11]; Ju and Koo, [12]; Lee and Han, [13]) etc.

In the study of Han [14], the price difference is not only increasing over time, the consumer continues to purchase the product with higher price difference of the price premium as well as the premium brands. Therefore, the majority of these products are mediated by culture and arts. These are sold at a higher price by about $10-20 \%$ compared to conventional products.

A company would have a more interest in the culture and art. The main goal of this study is first to select the product to apply the research, secondly to analyze empirical effects of cultural marketing, cultural marketing divided as detail cultural promotion, cultural synthesis, cultural style, on art marketing, and art marketing influences on recommendation. Third, we will analyze empirical effects of cultural marketing and art marketing to recommendation depending on premium price.

\section{Theoretical Background and Hypothesis}

\subsection{Cultural Marketing Type}

The cultural marketing concept can divide the culture for marketing and marketing for culture, general organization and cultural art of companies through a mutually beneficial relationship, both of win-win in terms can be found the significance of cultural marketing [15]. This study focuses on the "culture for marketing".

The type of culture marketing is classified into five types depending on the utilization of culture to the cultural promotion, cultural synthesis, cultural style, cultural support and the cultural spirit. This study focuses on product because the five types of cultural marketing select the configuration factors of the cultural promotion, the cultural synthesis and the cultural style. The remaining factors were excluded the cultural support and cultural spirit [16]. The cultural support is promoting provide the culture leverage from a strategic perspective of corporate. Part of a corporate social responsibility refers to the cultural activities to enhance the corporate and determine. That there is not connectivity product. The cultural spirit is utilizing a national cultural asset and images on the marketing of the corporate. A product has been judged by a different concept from the viewpoint of cultural images.

Cultural promotion refers to cultural images used for advertising, and promotes product sales in association with images of products. Therefore, the company leverages the culture as a means of advertising or sales promotion [17]. Cultural promotion is utilizing culture for sales and promotion activity. It can be called marketing to move purchase choice a consumer uses in imaging of a product. A study of Hagtvedt et al.[18], results from comparing consumer reactions to products do not reflect in art design, products reflect in art design was the consumer higher assessment of the product. These result, the art works aggressively utilizing in product and service, cultural promotion means that can have a positive impact on product image. A research about korean credit card companies of Song and Choi [19] divided by type of cultural marketing, verify each type influences on brand attitude, customer loyalty and recommendation through a parameter of corporate image. 
Cultural synthesis is a way that differentiates from other products to accumulate cultural images of the product or service. Compared to other cultural marketing methods, this type is one of the way to make the most of the cultural codes, in terms of utilizing 'cultural things' in forming an image of a product, and in promoting the product [20]. The Starbucks as example of cultural synthesis. Directing store atmosphere to fit the goal 'to sell the image of a cup'. The store was able to succeed in the positioning differentiated by place to home and work through the interior and music besides the coffee flavor and aroma. The art combination to bring up the imagination of mutual contact by providing a sensuous pleasure, as can have a favorable impact on consumer behavior [21]. The Art uped as a marketing means by reminiscent a positive effect on culture, education, knowledge, luxury and prestige, having a positive impact on the perception and evaluation of the entire property associated with the art. In particular, Cultural synthesis in the realm of visual elements is highlighted; product and package provides a universal art schema to consumers in the art images and a variety of aesthetic factors through links to each other.

Cultural style is to be positioned the company and products with as a symbol of a new distinctive culture [22]. Whistler is as a prime example of cultural styles. Whistler korea has showed exceptional value through differentiated art advertising a consumers want the cultural needs. Simply nary promote the brand image or product line, whistler has made a differentiated cultural marketing through a performance to express enjoying free in the selection of artists.

Considering the research findings, we propose the following hypotheses.

H1-1: Cultural promotion will positively effect on art marketing

H1-2: Cultural synthesis will positively effect on art marketing

H1-3: Cultural style will positively effect on art marketing

\subsection{Art Marketing and Recommendation}

Art Marketing is a type of cultural marketing, through exhibitions and performances and other artistic activities [23]. By introducing a package with a value of the art, people purchase not only the product, but also the feelings or moods from the artwork. Moreover, if a product would have more favorable design attracting the customers by its design and its brand value, it would likely to have more opportunities to get premium price [24].

One of the important cores of the 21st century, "culture" is situated. The art marketing perched with a best marketing strategies to enhance the corporate image and brand awareness. In an initial study of the art marketing was limited to the concept of product marketing more effectively, such as works of art, the art marketing today, however, is being described as covering the categories associated with the business and culture [25]. Therefore, sponsorship step of marketing for initial pure artwork as well as marketing utilizes art to increase profit of company, the art can be explained as the aggressive marketing strategies, that include both combines with art in the product production stage [26].

Words of mouth, defined as 'oral, person to person communication between a receiver and a communicator whom the receiver perceives as non-commercial, concerning a brand, a product or sevice' (Richins, [27]), has grown in research popularity since the mid 20th century. Consumers will often depend on the observation of knowledge on other consumer when making a purchasing decision [28], Recommendation has a positive impact on the purchasing decision. KatZ and Lazarsfeld [29], for instance, analyzed how WoM influences public opinion in 1995, and Engel et al. [30] found that, with respect to purchasing decisions, WoM is more effective than other marketing tools and conventional advertising media.

Others focused on how WoM affects organizations [31], with the general understanding that WoM shapes consumer desicion making (Parasuraman et al., [32]; 
Steffes and Burgee, [33]. Considering the research findings, we propose the following hypotheses.

$\mathrm{H} 2$ : Art marketing is positively related to recommendation.

\subsection{The Moderation Effect to Premium Price}

Premium pricing is the practice of keeping the price of a product or service artificially high in order to encourage favorable perceptions among buyers, based solely on the price [34]. The practice is intended to exploit the (not necessarily justifiable) tendency for buyers to assume that expensive items enjoy an exceptional reputation, are more reliable or desirable, or represent exceptional quality and distinction. Observed price premiums may vary depending on factors such as the type of industry [35] and the nature of a product. However, it is important to recognize that industry and product characteristics per se are not what drive price premium.

In a study of Zeithaml [36], since customers are willing to pay premium price for a product, expecting the product would be a good quality, it would have a positive impact on the probability of the product purchase. According to a study by Lee and Han [37], if the infusion of art as a product of design elements increases the aesthetic and symbolic features of the product, a premium price effect appears larger for the hedonic products than for practical products. Some writers, such as Doyle [38], even argue that a price premium is the most important way in which brands can create shareholder value, because it requires no direct investments to charge a higher price. It should be noted that price premium is the most in the present study, as well as in Sethuraman [39], deals with a willingness tp pay, which does not necessarily reflect real prices. Considering the research findings, we propose the following hypotheses.

H3-1: Premium price moderates the relationship between cultural promotion and art marketing

H3-2: Premium price moderates the relationship between cultural synthesis and art marketing.

H3-3: Premium price moderates the relationship between cultural style and art marketing. H4: Premium price moderates the relationship between art marketing and recommendation.

\section{Research Model and Method}

\subsection{Research Model}

Based on previous research, cultural marketing types have verified how it affected the art marketing, and the art marketing has positively affected the recommendation. In addition, we analyze empirical effects of cultural marketing and art marketing on recommendation depending on premium price. To this end, product selection, chosen art, brand names and pricing conducted a selection process. The research model in this study is shown in Figure 1. 


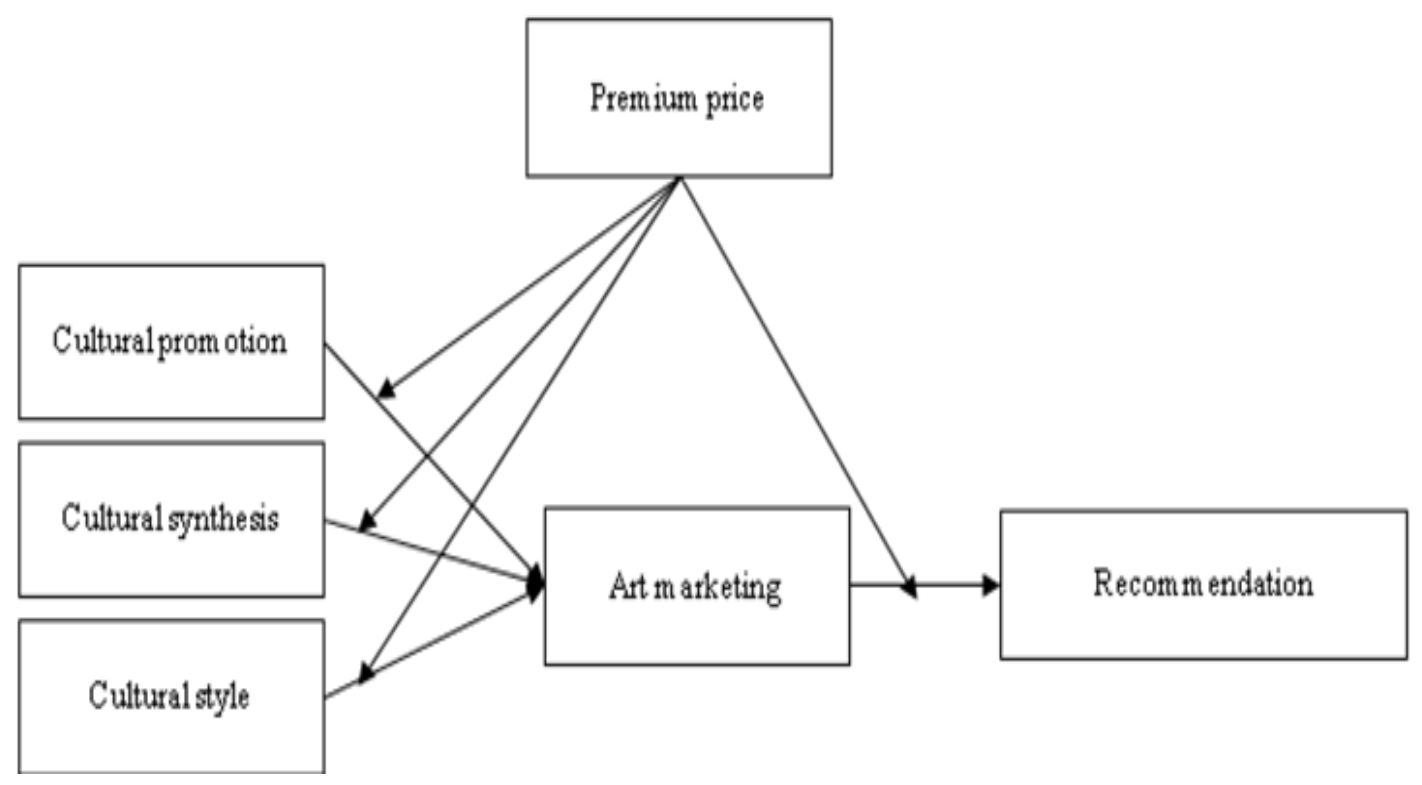

Figure 1. The Research Model

\subsection{Experimental Design}

3.2.1. Product, Art and Brand Name Selection: Experimental products of this study are relatively familiar products to consumers, who actually purchase the products. In addition, the products does not consider the particular brand upon purchase, the product were selected as a sample. Fewer than 45 of convenience goods were selected as bottled water.

Art design needed for the selection process was carried out in the study. Except for the art design, major and related workers, 24 people participated in the experiment.

In the secondary preliminary research, an advertisement was created by using the product and art, price and brand name for the advertisement. In the second preliminary research, 25 subjects participated; marketing professors and doctoral students in Dept. of Business Administration. Five names were extracted from the research and the frequency analysis was carried out. The brand name select items are measured by modifying questions with fitness, in Zajonc and Markus [40] "Do you think the name it fits well the name of the product?", and a questionnaire was measured using a 7-point scale. Bottled water brand name fitness of "Art Water" $(\mathrm{M}=5.08, \mathrm{SD}=1.55)$ was chosen to appear.

\subsection{Scale Measures}

The research has five constructs, each having multiple items that are measured using a seven-point Likert-type scale ( $1=$ strongly disagree and $7=$ strongly agree). Table 1 is a measurement of variables and author. 
Table 1. Measurement of Variables and Author

\begin{tabular}{|c|c|c|}
\hline Variables & Measures / 7 Likert-type scale & Authors \\
\hline \multirow{3}{*}{$\begin{array}{l}\text { Cultural } \\
\text { promotion }\end{array}$} & $\begin{array}{l}\text { In informing the bottled water, arts are used actively as a } \\
\text { part of advertising. }\end{array}$ & \multirow{9}{*}{$\begin{array}{c}\text { Kim, Y. Y. [41], } \\
\text { Ch, O.Y. et al [42], } \\
\text { Han, S. C [43] } \\
\text { Chu, S. Y. [44] }\end{array}$} \\
\hline & $\begin{array}{l}\text { In informing the bottled water, arts are used actively as a } \\
\text { part of advertising. }\end{array}$ & \\
\hline & $\begin{array}{l}\text { In informing the bottled water, arts are used actively as a } \\
\text { part of advertising. }\end{array}$ & \\
\hline \multirow{3}{*}{$\begin{array}{l}\text { Cultural } \\
\text { synthesis }\end{array}$} & The design of the bottle reminds of cultural image. & \\
\hline & $\begin{array}{l}\text { The cultural design on the bottle gives cultural image } \\
\text { effectively. }\end{array}$ & \\
\hline & Directing culture in the bottled water. & \\
\hline \multirow{3}{*}{$\begin{array}{l}\text { Cultural } \\
\text { style }\end{array}$} & Symbolized a new culture with art to the bottled water. & \\
\hline & Symbolized a unique culture with art to the bottled water & \\
\hline & $\begin{array}{l}\text { Symbolized a differentiated culture with art to the bottled } \\
\text { water. }\end{array}$ & \\
\hline \multirow{3}{*}{$\begin{array}{c}\text { Art } \\
\text { marketing }\end{array}$} & The works of art are used actively for marketing. & \multirow{3}{*}{$\begin{array}{l}\text { Lee \& Han [13], } \\
\text { Lee et al..,[45] }\end{array}$} \\
\hline & The promotional activities are used by a work of art. & \\
\hline & The work of art leverage in the product design. & \\
\hline \multirow{2}{*}{$\begin{array}{l}\text { Recom } \\
\text { mendation }\end{array}$} & I would like to recommend this product to others. & \multirow{2}{*}{$\begin{array}{c}\text { Morgan\&Hunt [46], } \\
\text { Reynolds\&Bcatty } \\
{[47]}\end{array}$} \\
\hline & I am thinking of recommending this product to others. & \\
\hline
\end{tabular}

\section{Methodology}

This survey was carried out with 214 (55.1\%/Male, 44.9\%/Female) university student and common people understanding of high PR and marketing professionals for art marketing. The study was carried out from March 3, 2014 to March 24, with 214 questionnaires, 16 questionnaires were eliminated due to missing data, resulting in final samples of 198. Analysis was conducted with AMOS 18.0 and SPSS 20.0. Table 2 showed that demographic statistics.

Table 2. Demographic Statistics

\begin{tabular}{|c|c|c|c|}
\hline construct & & frequency & percent \\
\hline \multirow[b]{2}{*}{ Gender } & Male & 109 & $55.1 \%$ \\
\hline & Female & 89 & $44.9 \%$ \\
\hline \multirow{4}{*}{ Age } & $20 \sim$ & 126 & $61.2 \%$ \\
\hline & $30 \sim$ & 39 & $18.9 \%$ \\
\hline & $40 \sim$ & 30 & $14.6 \%$ \\
\hline & $50 \sim$ & 3 & $1.5 \%$ \\
\hline \multirow{3}{*}{ Academic background } & Bachelor degree & 104 & $50.5 \%$ \\
\hline & Master degree & 24 & $11.7 \%$ \\
\hline & Doctoral degree & 69 & $33.5 \%$ \\
\hline \multirow{3}{*}{ Occupation } & Student & 132 & $64.1 \%$ \\
\hline & Office worker & 32 & $15.5 \%$ \\
\hline & Self-employed & 33 & $16.0 \%$ \\
\hline \multirow{4}{*}{ Interest in Culture and art } & Not interested in at al & 12 & $5.8 \%$ \\
\hline & Not interested & 58 & $28.1 \%$ \\
\hline & normal & 79 & $38.3 \%$ \\
\hline & Be interested & 49 & $23.9 \%$ \\
\hline \multicolumn{2}{|c|}{ Total } & 198 & $100 \%$ \\
\hline
\end{tabular}

\subsection{Confirmory Factor and Correlation Analysis}


Confirmatory factor analysis was used to assess the unidimensionality and validity of the constructs (Table 3). First, Cronbach's alpha is estimated to obtain a measure of reliability of a set of question items [48]. A widely advocated level of adequacy for coefficient alpha has been at least 0.8 [49]. From table 3, we can see that the Cronbach's alpha of each variable is higher than the standard of 0.7 , indicating a good reliability of the variables. Second, standardized loading estimates are above the 0.6 threshold. Moreover, composite reliabilities for each dimension ranges from 0.877 to 0.960 . The indexes suggest that a reasonable fit, as would be expected given model $\left(\mathrm{x}^{2}(\mathrm{df})=123.716(77), \mathrm{p}=.000, \mathrm{CMIN} / \mathrm{DF}=1.586, \mathrm{GFI}=.927, \mathrm{AGFI}=.888, \mathrm{IFI}=.983\right.$, $\mathrm{TLI}=.977, \mathrm{CFI}=.983, \mathrm{RMR}=.076, \mathrm{RMSEA}=.055)$. Overall, the result supports the theoretical measurement model.

Table 3. Confirmory Factor Analysis

\begin{tabular}{|c|c|c|c|c|c|}
\hline Type Construct & Item & Estimate & Cronbach' $\propto$ & CR & AVE \\
\hline \multirow{3}{*}{ Cultural promotion } & CA3 & $.736^{\star \star \star}$ & \multirow{3}{*}{.896} & \multirow{3}{*}{.904} & \multirow{3}{*}{0.760} \\
\hline & CA2 & $.928^{\star * *}$ & & & \\
\hline & CA1 & $.938^{\star \star *}$ & & & \\
\hline \multirow{3}{*}{ Cultural synthesis } & CD3 & $.797^{* \star *}$ & \multirow{3}{*}{.910} & \multirow{3}{*}{.913} & \multirow{3}{*}{0.779} \\
\hline & CD2 & $.935^{\star \star \star}$ & & & \\
\hline & CD1 & $.911^{* \star *}$ & & & \\
\hline \multirow{3}{*}{ Cultural style } & CS3 & $.767^{* \star *}$ & \multirow{3}{*}{.874} & \multirow{3}{*}{.877} & \multirow{3}{*}{0.705} \\
\hline & CS2 & $.849^{\star \star \star}$ & & & \\
\hline & CS1 & $.898^{* \star *}$ & & & \\
\hline \multirow{3}{*}{ Art marketing } & ART3 & $.919^{* * *}$ & \multirow{3}{*}{.960} & \multirow{3}{*}{.960} & \multirow{3}{*}{0.890} \\
\hline & ART2 & $.973^{\star \star \star}$ & & & \\
\hline & ART1 & $.938^{* * *}$ & & & \\
\hline \multirow{3}{*}{ Recommendation } & R3 & $.705^{\star * \star}$ & \multirow{3}{*}{.902} & \multirow{3}{*}{.909} & \multirow{3}{*}{0.773} \\
\hline & $\mathrm{R} 2$ & $.968^{\star \star \star}$ & & & \\
\hline & $\mathrm{R} 1$ & $.941^{* \star *}$ & & & \\
\hline $\begin{array}{l}(\mathrm{df})=123.716(77), \\
\mathrm{CFI}=.983, \mathrm{RMR}=.0\end{array}$ & $\begin{array}{l}.000, \mathrm{C} \\
\mathrm{RMSE}\end{array}$ & $=1.586$ & & & $I=.977$ \\
\hline
\end{tabular}

Comparing the variance extracted (AVE) estimates for each construct with the squared inter-construct correlations between the relevant constructs gives an indication of discriminant validity (see Table 4). The results show that AVE is greater than the squared correlation estimate for each construct pair, providing additional support of discriminant validity [50].

Table 4. Correlation Analysis

\begin{tabular}{cccccc}
\hline Type Construct & 1 & 2 & 3 & 4 & 5 \\
\hline Cultural promotion & .760 & & & & \\
\hline Cultural synthesis & .384 & .779 & & & \\
\hline Cultural style & .409 & .448 & .705 & & \\
\hline Art marketing & .081 & .016 & .016 & .890 & .773 \\
\hline Recommendation & .152 & .202 & .291 & .129 & 3.84 \\
\hline M & 4.89 & 4.77 & 4.37 & 3.55 & 1.49 \\
\hline SD & 1.23 & 1.24 & 1.30 & 1.31 & \\
\hline
\end{tabular}

Notes: AVE for reflective constructs are on the diagonal.

\subsection{Hypothesis Testing and Moderating Effects}


The fit indices of the research model shown in Table 5 are acceptable. $\left(\mathrm{x}^{2}(\mathrm{df})=\right.$ 110.369(78), $\mathrm{p}=.000, \mathrm{CMIN} / \mathrm{DF}=1.415$, GFI=.935, AGFI=.900, IFI=.988, TLI=.984, $\mathrm{CFI}=.988, \mathrm{RMR}=.078$, RMSEA=.046). The result of hypothesis testing is shown in Table 5. for four hypotheses. The Cultural synthesis $(\mathrm{C} . \mathrm{R}=2.067$ and $\mathrm{p}=.039)$ and cultural style $(\mathrm{C} . \mathrm{R}=2.053$ and $\mathrm{p}=.040)$ have positive effects on the art marketing. The cultural promotion (C.R=-.834 and $\mathrm{p}=.404$ ) have a negative effect on the art marketing. Finally art marketing $(C . R=6.435$ and $p=.000)$ has a positive effect on the recommendation.

Table 5. Results of Hypothesis Testing

\begin{tabular}{|c|c|c|c|c|c|c|}
\hline \multicolumn{2}{|c|}{ Hypotheses Tests } & \multirow{2}{*}{$\begin{array}{l}\text { Estimat } \\
\mathrm{e} \\
-.089\end{array}$} & \multirow{2}{*}{$\begin{array}{l}\text { S.E. } \\
.143\end{array}$} & \multirow{2}{*}{$\begin{array}{l}\text { C.R. } \\
-.834\end{array}$} & \multirow{2}{*}{$\begin{array}{l}p- \\
\text { value } \\
.404\end{array}$} & \multirow{2}{*}{$\begin{array}{c}\text { Result } \\
\text { Rejected }\end{array}$} \\
\hline $\mathrm{H} 1-1$ & Cultural promotion $\rightarrow$ Art & & & & & \\
\hline $\mathrm{H} 1-2$ & Cultural synthesis $\rightarrow$ Art & .239 & .142 & 2.067 & .039 & Accepted \\
\hline $\mathrm{H} 1-3$ & Cultural style $\rightarrow$ Art & .248 & .141 & 2.053 & .040 & Accepted \\
\hline $\mathrm{H} 2$ & Art $\rightarrow$ Recommendation & .392 & .068 & 6.435 & .000 & Accepted \\
\hline $\begin{array}{l}(\mathrm{df})= \\
\mathrm{CFI}=\end{array}$ & RMR $=.078$, RMSEA $=$ & & & & & \\
\hline
\end{tabular}

As the main effects were found to be significant, the proposed moderating effects were examined based on the previous studies. The sample was divided into two subgroups by visiting frequency, which was measured with interval scale [51]. The proposed model was run by freeing key interested paths, whereas a restricted model assumed that the key paths are equal across the subgroups. The bottled water reveals that the premium price level has significant moderating effects on the paths from and cultural style to art marketing, but does not in the linkages from cultural promotion and cultural synthesis to art marketing. Finally, the result is the same from art marketing to recommendation.

Table 6. Moderating Effects

\begin{tabular}{|c|c|c|c|c|c|c|}
\hline \multirow{2}{*}{\multicolumn{2}{|c|}{ Path }} & High $(n=72)$ & Low $(n=72)$ & \multirow{2}{*}{$\begin{array}{l}\text { Free } \\
\text { Model }\end{array}$} & \multirow{2}{*}{$\begin{array}{l}\text { C. } \\
\text { Model }\end{array}$} & \multirow{2}{*}{$\Delta X^{2}(1)$} \\
\hline & & Estimate $/ \mathrm{t}$ & Estimate $/ \mathrm{t}$ & & & \\
\hline H5 & Cultural prom $\rightarrow$ Art & $-.167 /-1.229$ & $-.068 /-.450$ & \multirow{4}{*}{264.254} & 264.407 & 0.153 \\
\hline $\mathrm{H} 6$ & Cultural syn $\rightarrow$ Art & $.087 /-.592$ & $.402 /-2.725$ & & 266.529 & 2.275 \\
\hline $\mathrm{H} 7$ & Cultural style $\rightarrow$ Art & $.519 / 3.149$ & $.033 / .245$ & & 269.699 & $5.445^{\star *}$ \\
\hline $\mathrm{H} 8$ & Art $\rightarrow$ Recommend & $.493 / 5.874$ & -.261 & & 268.037 & $3.783^{* *}$ \\
\hline
\end{tabular}

\section{Conclusions}

The conclusion of this study reveals that cultural marketing has partial effects on the art marketing. The bottled water product has positive effects on art marketing of cultural syntheses and cultural style. However, cultural promotion has negative effects on the art marketing. This study shows that cultural promotion does not have a positive impact on art marketing for products. Cultural promotion among cultural marketing activities has the lowest impact on the product package. If you use it for commercial purposes, as well. Cultural consumers are carefully planning the cultural promotional activities related to mean the possibility of negative recognize the cultural marketing of the company, will be approached.

In this study, cultural synthesis activity appeared to have a positive impact as in the previous studies (Han, [14]; Kim, [25]). Companies have used a variety of methods to improve the brand image; it has been recognized as one of the methods of the culture synthesis activity. A corporation could be more effective with an indirect approach 
through cultural synthesis than direct marketing tool such as cultural promotion, because to insert the paintings and artistic elements in the package or the advertising of products. As product image to recognize height of the product itself. To effectively grant a cultural synthesis with the product, and should actively utilize the art. And will have a greater focus for cultural synthesis that can steadily increase the corporate image over the long term than cultural promotion.

Culture style is positioning in corporate image as a new and unique image, and other companies showing differentiate appeared to form a positive influence. If this study has confirmed focusing on the relationship between the product and cultural style, and the result is also shown to have a positive impact. Companies should increase the perception of premium products by actively utilizing cultural elements in the development process of re-positioning of existing products and new products. Specifically, the companies should be positioning to symbolize a new culture, a unique culture and differentiation culture, and infusion to the art on a product. In addition, positioning is focused on the product image will be more effective than the corporate image.

Moreover, art marketing has positive effects on recommendation. With premium price, each cultural syntheses and cultural style has a positive effect on art marketing of the bottled water product. On the other hand, cultural promotion has negative effects on art marketing. Lastly, the premium price positively moderates the effect of art marketing on recommendation.

This study has the following limitations:

Increase value for products in the consumer, should be utilized as strategic a cultural marketing means of ensuring the corporate short- and long-term profits, sale increase and sustainable competitive advantage.

First, a representative sample limits. This survey was carried out with university student and common people understanding of high PR and marketing professionals for art marketing and cultural marketing. In subsequent studies, we need to expand research on consumers, and would be performed by the study of the various layers.

Secondly, since the research was conducted with virtual brand, not brands that already exist, there might be discrepancy between the actual result with real brand and the limited result with virtual product. Therefore, further research needs to be performed by actual brand.

\section{References}

[1] S. C. Kim, "Study on Advertising Art Infusion", Doctoral Dissertation, Graduate school of Dong-A University in Korea, (2010).

[2] S. Y. Pak, "Let's Start Knowing as Cultural Marketing Customer", www.kmarketing.co. kr.

[3] H. Y. Jang and G. Khongorzul, "The Influence of Cultural Marketing on Recommendation: Focused on the Moderation Effect of Premium Price", The Academy. Customer Satisfaction, Management, vol. 17, no. 1, (2015), pp. 43-65.

[4] G. Sorman, "Le Monde Est ma Tribu", Librairie Generale Francaise, (1999).

[5] D. S. Kwak, Y. W. Park and S. Y. Woo, "A Study of The Effects of Cultural Promotion Sales on Brand Images and Brand Attitude: Focusing on the Moderating Effect of Product Invol..vement", Arts Management. Research, vol. 26, no. 5, (2013), pp. 5-34.

[6] J. H. Nam, "Study on the Effects of Corporate Associations on Brand Credibility : With Premium Brand as Paramete", Master Dissertation, Brand Management Major of Hongik University in Korea, (2013).

[7] C. U. Kwak, "The Influence of Corporate Image of Culture Marketing in Tourism Companies on Brand Equity and Continuous Relation Intention: Focused on Airlines and Travel Agency", Doctoral Dissertation, Graduate School of Kyonggi University in Korea, (2013).

[8] H. G. Kahn, J. H. Ryu and H. A. Choi, "Is Branding Culture Marketing Activities Better for Corporate Images?", Korean Academy. Commodity Science \& Technology, vol. 30. no. 2, (2012), pp. 9-18.

[9] M. A. Ryu and O. R. Park, "A Study on the Corporate Image and Clothes Purchasing Behavior Depending on the Degree of Interest in Cultural Marketing - Focusing on Uniqlo Brand", Daehan Academy. Management Information Systems, vol. 31, no. 1, (2012), pp. 1-21. 
[10] Y. Ch. Lee, "The Influence on Consumers of Art Collaboration Expression Type of Cosmetic Package Commercial: Centering Around Art Accept Type and Brand Crossing Type", Master Dissertation, The Graduete School of Advertising and Public Relations Hong-ik University, (2015).

[11] J. H. Leem and H. B. Lee, "The Effect of Art Advertisement and Anchoring on the Ad Comprehension and the Attitude Toward Ad", The Korean Journal. Advertising, vol. 23, no. 4, (2012), pp. 49-75.

[12] S. H. Ju and D. M. Koo, "Effect of the Characteristics of Art Collaboration Products on Customers' Perceived Value and Product Purchasing Intention", The Korean Journal. Marketing, vol. 22, no. 2, (2014), pp. 101-123.

[13] J. U. Lee and Y. H. Han, "Effect of Art Infusion on Consumer Evaluation: Focusing on Product Types", Korean Journal. Consumer Advertising Psychology, vol. 11, no. 4, (2010), pp. 797-821.

[14] Y. H. Han, "A Study on the Art Infusion as Design Components", Korean Design Knowledge Society, vol. 27, no. 9, (2013), pp. 203-215.

[15] S. Y. Kim, S. H. Im and J. K. Goo, "The Scale Development of Cultural Marketing”, Korean Journal, Product Research, vol. 29, no. 6, (2011), pp. 119-131.

[16] G. Khongorzul, J. S. Noh and H. Y. Jang, "The Antecedents and Outcomes of Art Marketing: Focus on the Moderation Effect of Premium Prie", Advanced Science. Technology Letters, vol. 114, (2015), pp. $72-76$.

[17] S. Yon Pak, "Let's Start Knowing as Cultural Marketing Customer", www.kmarketing.co. kr.

[18] H. Hagtvedt and V. M. Patrick, "Art Infusion: The Influence of Visual Art on The Perception and Evaluation of Consumer Products", Journal pf Marketing. Research, vol. 45, no. 3, (2008), pp. 379-389.

[19] J. S. Song and M. H. Choi, "Culture Marketing Effects on Enterprise-Image, Customer Loyalty, and Recommendation Intention: The Case for Credit Card Companies", The Korean Journal, Management Education, vol. 80, (2013), pp. 481-501.

[20] S. H. Shin, S. P. Lee and W. S Cheo, "Study of Cultural PR Advertisement in The Samsung Electronic Companies: Focused on Consumer Code and Product Materialism", Korean Advertising Society (2004), vol. 6, no. 3, pp. 80-125.

[21] S. O. Kim, "The Effect of the Product Placement(PPL) on Brand Image and Purchase Intention in Foodservice Industry", Doctoral Dissertation, The Graduate School of Kyonggi University, (2008).

[22] H. S. Gan, C. H. Ryu and H. N. Chue, "The Influence of New Cultural Marketing Branding on Corporate Image", Korean Product Society, vol. 30, no. 2, (2012), pp. 9-18.

[23] S. L. Kim, "The Study of Financial Institutions Cultural Marketing Awareness and Activation", Doctoral Dissertation, Graduate School of Myongchi University, (2013).

[24] Y. H. Han, "The Study of Art Infusion in Design", Korean Design Society, vol. 27, (2013), pp. 203-215.

[25] S. J. Kim, "The Effect of the Advertising with Art Infusion", Doctoral Dissertation, Graduate School, Dong-A University Busan Korea, (2009).

[26] R. W. Veryzer, "A Nonconscious Processing Explanation of Consumer Response to Product Design", Psychology Marketing, vol. 16, no. 6, (1999), pp. 497-522.

[27] L. M. Richins, "Negative Word-of-Mouth by Dissatisfied Consumers: A Pilot Study", Journal of Marketing Research, vol. 47, no. 1, (1983), pp. 68-78.

[28] Dichter and Ernest, "How Word of Mouth Advertising Works", Harvard Business Reviews, (1966) November-December, pp. 147-157.

[29] E. Katz and P. F. Lazarsfeld, "Personal Influence: the Part Played by People in the Flow of Mass Communications", Transaction Pub.

[30] J. E. Engel, R. D. Blackwell and R. J. Kegerreis, "How Information is Used to Adopt an Innovation", Journal of Advertising Research, vol. 9, no. 3, (1969), pp. 3-8.

[31] D. E. Garrett, "The Effectiveness of Marketing Policy Boycotts: Envirinmental Opposition to Marketing”, Journal of Marketing, vol. 51, no. 2, (1987), pp. 46-57.

[32] A. Parasuraman, V. A. Zeithaml and L. L. Berry, "A Conseptual Model of Service Quality and its Implications for Future Research", Journal of Marketing, vol. 49, (1985), pp. 41-50.

[33] E. M. Steffes and L. E. Burgee, "Social Ties and Online Word of Mouth", Internet Research, vol. 19, no. 1, (2009), pp. 42-59.

[34] G. Gittings, "The Advertising”, Handbook. New York: Routledge.

[35] N. Mizik and R. Jacobson, "Trading Off between Value Creation and Value Approprition: The Financial Implications of Shifts in Strategic Emphasis", Journal of Marketing, vol. 67, (2003) January, pp. 63-76.

[36] Zeithaml, 'Consumer Perceptions of Price, Quality and Value: A Means-End-Synthesis Of Evidence", Journal of Marketing Research, vol. 52, no. 3, (1988), pp. 2-22.

[37] Y. H. Han and C. I. Lee, "Effects of Art Infusion on Luxury Perceptions: Focus on The Moderating Effects of Product and Brand Concept Types", Korean Advertising Research, vol. 22, no. 5, (2010), pp. 69-97.

[38] P. Doyle, "Shareholder-Value-Based Brand Strategies", Journal of Brand Management, vol. 9, no. 1, (2001), pp. 20-30.

[39] R. Sethuraman, "What Makes Consumers Pay More for National Brands th.an for Private Labels Images or Quality", Marketing Science Institute Paper Series, Cox School of Business, Southern Methodist University. 
[40] R. B. Zajonc and H. Markus, "Affective and Cognitive Factors in Preferences", Journal of Consumer Research, vol. 9, (1982), pp. 123-131.

[41] Y. Y. Kim, "Empirical Study on the Influence of Corporation Image and Formation of Brand Asset with Cultural Marketing", Doctoral Dissertation, Jeonju University of Korea, (2006)

[42] Y. Y. Zhou, P. Du, Y. H. Moon and J. Choi, "Effects of Cultural Marketing Activities on Consumer Response: The Mediating Role of Corporate Association", Journal of Culture Industry, vol. 13, no. 1, (2013), pp. 35-42.

[43] S. J. Han, "A Study on Brand Loyalty of The Food Service Industry that Employs Culture Marketing", Doctoral Dissertation, The Graduate School of Anyang University, (2008).

[44] S. Y. Cho, "Impacts of Culture Marketing of Coffee-Specialized Shops on the Company Image and Consumer- Company Identification and Brand Equity", Doctoral Dissertation, The Graduated School of Sungshin Women's University, (2010).

[45] M. K. Lee and Y. Y. Moon, "Effects of Culture Marketing Versus Traditional Marketing Activities on Consumer Store Evaluations and Loyalty”, Journal of Marketing of Korea, vol. 13, no. 2, (2008), pp. 121.

[46] R. P. Morgan and R. Hunt, “The Commitment Trust Theory of Marketing”, Journal of Marketing, vol. 58, (1994) July, pp. 20-38

[47] K. E. Reynolds and S. E. Beatty, "A Relationship Customer Typology”, J. Retailing, vol. 75, no. 4, (1999), pp. 509-523.

[48] R. J. Kyle and R. K. Henson, "A Confirmatory Factor Analysis of a New Measure of Teacher Efficacy: Ohio State Teacher Efficacy Scale”, The American Educational Research, (2001) April, pp. 10-14.

[49] J. M. Cortina, "What is Coefficient alpha? An Examination of Theory and Applications", Journal of Applied Psychology, vol. 78, no. 1, (1993), pp. 98-104.

[50] R. P. Bagozzi and P. A. Dabholkar, "Consumer Recycling Goals and Their Effect on Decisions to Recycle: A Means-end Chain Analaysis", Psychology Marketing, vol. 11, no. 4, (1994), pp. 313-340.

[51] Carroll and Ahuvia, "Corporate Social Responsibility", Business Society, vol. 32, no. 2, (2006), pp. 268295

\section{Authors}

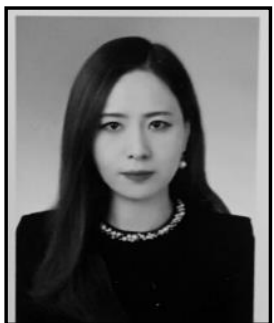

Gantumur Khongorzul, First Author, was born in Erdenet City, Mongolia. She is the candidate for Phd. in Gyeonsang National University. She is now Bk 21 plus researchers (Brain Korea 21 Program for Leading Universities \& Students). Her research interests include hotel service, consumer behavior, arts marketing and marketing strategy.

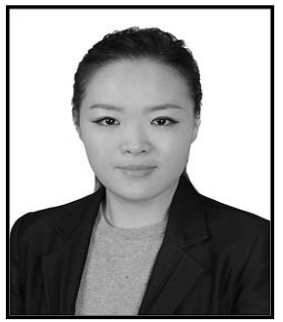

JeongSukNoh, Co Author, was born in Geochang province, South Korea. She is the candidate for Phd. in Gyeongsang National University. She is currently lecturer of the Korean Information Technical Education and Bk 21 plus researchers (Brain Korea 21 Program for Leading Universities \& Students) and also teaches IT technical trainings to the local area. Her research interests include educational service, relationship marketing, consumer conduct and web contents

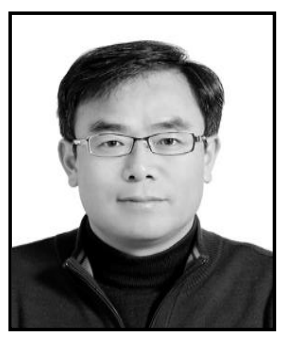

Hyeong-Yu Jang, Corresponding Author, is Associate Professor at the Department of Business Administration and senior researcher of business and economics research institute, Gyeongsang National University. He received Ph.D. degree in B. A. from the GNU and now is serving as visiting scholars in California State University. He served as not only the Leader of Entrepreneurship Training Center and Career Counseling Center Director, but also director and editor in chief in Korea Institute of Marketing and E-Commerce Association. His research focuses on online marketing management, festival and tourism management relationship marketing, consumer behavior and 
International Journal of $u-$ and e- Service, Science and Technology

Vol.9, No. 3 (2016)

new product diffusion. His papers have been appeared in lots of Korea main management/business journals and renowned international journals including SSCI and SCOPUS. 